\title{
Colecionando arte e antropologia: controvérsias nos museus de Barcelona
}

Collecting art and anthropology: controversies in the museums of Barcelona

\author{
Renata Montechiare* \\ *Faculdade Latino-Americana de Ciências Sociais - Rio de Janeiro, RJ, Brasil \\ rmontechiare@gmail.com \\ https://orcid.org/0000-0003-2466-5843
}




\title{
Resumo
}

O trabalho aqui apresentado pretende percorrer acontecimentos que circundaram museólogos, antropólogos e historiadores da arte ao menos desde 2011 em Barcelona. Trata de acompanhar os desdobramentos da reclassificação da Coleção Folch de "arte exótica" e as implicações da exibição de seus objetos em dois museus da cidade. Os relatos sobre fatos, notícias, documentos e decisões aqui expostos foram coletados prioritariamente a partir de entrevistas com os profissionais envolvidos. Estes narraram a seu modo a sequencia de ocorrências que desencadeou disputas em torno dos conceitos de "arte" e "antropologia" quando atribuídos às coleções. Propõe-se, portanto, seguir esses acontecimentos para a partir deles debater as transformações recentes no campo dos museus etnográficos.

Palavras-chave: museu etnográfico; coleções; arte; antropologia.

\begin{abstract}
This work aims to cover events that have surrounded museologists, anthropologists and art historians at least in the last five years in Barcelona. It tries to follow the after-effects of the reclassification of the "exotic art" Folch Collection and the consequences of its exhibition in two museums in town. The stories, facts, news, documents and decisions presented here were collected primarily from interviews with the professionals involved. They told in their own way the sequence of occurrences that triggered disputes around the concepts of "art" and "anthropology" when attributed to collections. We propose, therefore, to follow these events in order to discuss the recent changes in the field of ethnographic museums.
\end{abstract}

Keywords: ethnographic museum; collections; art; anthropology. 


\section{Introdução ${ }^{1}$}

No fim do ano de 2014, o campo dos museus de Barcelona foi agitado por severas críticas atribuídas às escolhas de seus dirigentes políticos quanto aos rumos das instituições. O manifesto Barcelona i els museus com a pessebres ${ }^{2}$ foi publicado em dezembro desse ano e assinado por cerca de 80 professores da Universitat de Barcelona, a maioria deles antropólogos. O texto acusava a política cultural do então prefeito de "coisificar" a cultura catalã e "estetizar" coleções de territórios que integraram o império espanhol, transformando-as em "obras de arte" à moda ocidental europeia. Por um lado, criticava o antigo Museo Etnológico de Barcelona, que àquela data permanecia fechado há quase quatro anos, de se reestruturar como um museu contaminado pela "maré identitária" da Catalunha atual. Referia-se às mobilizações pela independência em relação à Espanha, e à atitude do museu de reificar o presente sem considerar as relações e negociações que a cultura pressupõe. Por outro lado, acusava o novo Museo de Culturas del Mundo, inaugurado dois meses depois, de "consagração superficial do exotismo" numa chave aproximada da experiência colonial que deu origem às coleções, e de tratar-se de um museu dedicado ao turismo de massa celebrado pelo "modelo (de cidade) Barcelona".

Nesse panorama, a pesquisa de campo na cidade ${ }^{3}$ revelou argumentos controversos articulados em torno de uma coleção privada de objetos etnográficos reunidos em meados do século XX por importantes personagens locais. As disputas a partir das reclassificações dos objetos da Coleção Folch configuraram-se como um caso que aponta questões contemporâneas sobre a atualização de museus etnográficos e suas coleções, permitindo conhecer os desafios enfrentados pelos profissionais que se dedicam a criar e/ou manter museus abertos ao público nos dias de hoje.

Acompanhando as narrativas desses profissionais sobre um museu de finais dos anos 1940 e outro recentemente inaugurado (em 2015), busco conhecer o

1 Este texto utiliza trechos reformulados da tese de doutorado da autora (Montechiare, 2017). Título inspirado no artigo de James Clifford "Colecionando arte e cultura” (Clifford, 1994).

2 "Barcelona e os museus como presépios" (cf. Barcelona..., 2014).

3 Entre setembro de 2015 e março de 2016. 
processo de formação das coleções, os critérios e interesses dos envolvidos em organizá-las e exibi-las, e o ambiente de concepção dos museus em questão.

$\mathrm{O}$ trabalho aqui apresentado pretende percorrer acontecimentos que circundaram museólogos, antropólogos e historiadores da arte ao menos nos últimos cinco anos em Barcelona. Trata de acompanhar os desdobramentos da reclassificação da Coleção Folch de "arte exótica" e as implicações da exibição de seus objetos em dois museus da cidade. Os relatos sobre fatos, notícias, documentos e decisões aqui expostos foram coletados prioritariamente a partir de entrevistas com os profissionais envolvidos. Estes narraram a seu modo a sequencia de ocorrências que desencadeou disputas em torno dos conceitos de "arte" e "antropologia" quando atribuídos às coleções. Propõe-se, portanto, seguir esses acontecimentos para a partir deles debater as transformações recentes no campo dos museus etnográficos.

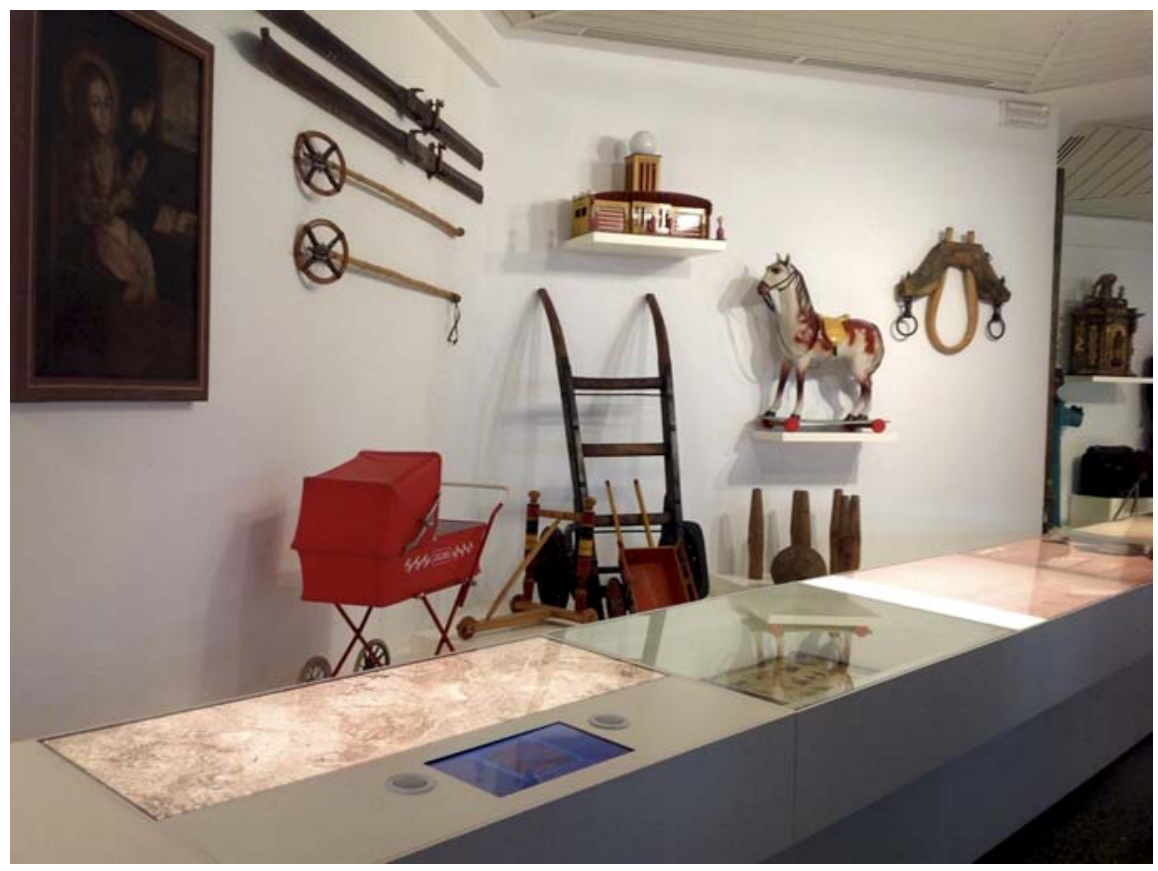

Figura 1. Objetos em exposição no Museo Etnológico de Barcelona (foto: acervo pessoal da autora, 2015). 


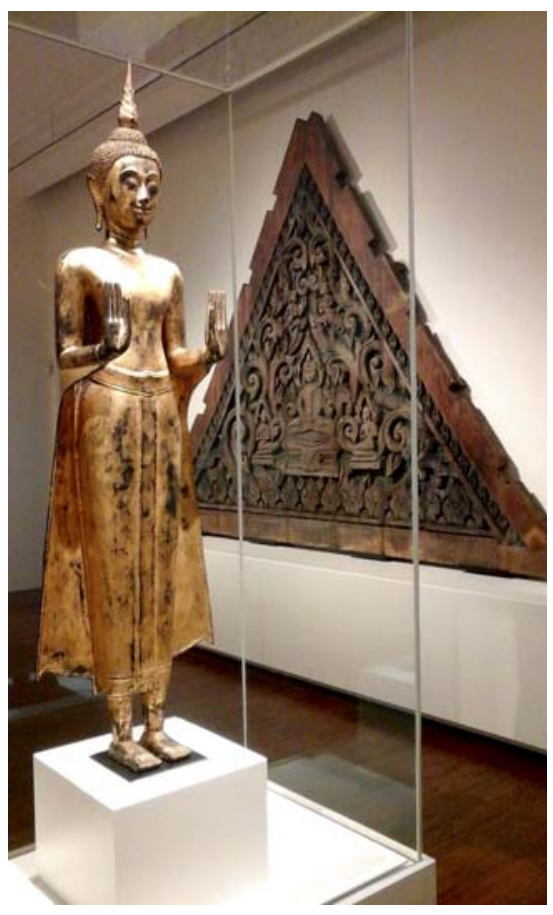

Figura 2. Objetos em exposição no Museo de Culturas del Mundo de Barcelona (foto: acervo pessoal da autora, 2015).

\section{Museus etnográficos em transformação}

Os atuais debates sobre as renovações de museus antropológicos na Europa trazem aspectos conflituosos e argumentos de defesa ou acusação das posições assumidas pelas instituições ao exibir suas coleções. O papel desempenhado pelos museus em diálogo com a antropologia desde meados do século XIX vem transformando-se e reunindo novos atores sociais, especialmente os originários do cenário pós-colonial.

Quanto à antropologia, cabe observar a relevância de pesquisas sobre cultura material, marcante até os anos 1920 e 1930, décadas que consolidariam a observação participante como prática dos antropólogos e "a apreensão das sociedades como entidades isoladas e únicas que se identificam pelas suas instituições e crenças particulares" (Duarte, 1998, p. 122). A partir daí, a antropologia passa por uma forte dissociação do interesse relativo à cultura material, ao valor intrínseco dos objetos e à própria prática museológica (Gonçalves, 1995). 
Entretanto, a renovação do interesse pelo campo dos museus a partir dos anos 1980 abre paradigmas até então pouco explorados, enxergando-os como instituição social e a cultura material como prática social (Gonçalves, 1995). Tornam-se objeto de estudos, e não mais laboratórios de análises das culturas através das peças trazidas por missionários e expedições para comparações entre sociedades dispersas (Bennett, 1995; Conklin, 2013; Dias, 1991; Findlen, 1994).

Diante do universo de questionamentos sobre a legitimidade da aquisição, guarda e exibição de objetos coletados em períodos coloniais, os museus vêm enfrentando dilemas quanto às alternativas de exibição das coleções que possuem. Nesse sentido, a opção por reinterpretar objetos chamados "etnográficos" como "obras de arte" tornou-se estratégia empregada por importantes instituições.

Em Barcelona, os profissionais de museus viram-se imersos em decisões a respeito da forma mais adequada de exibir suas coleções, e enfrentaram argumentos interdisciplinares muitas vezes contrastantes. A reclassificação dos objetos como "arte" ou "antropologia" opôs campos dos conhecimentos, instituições e seus trabalhadores. Cenário favorável para a investigação sobre os dilemas das escolhas disponíveis.

No contexto de mudanças em museus pela Europa, talvez o caso mais emblemático das últimas décadas tenha sido a inauguração do Musée du quai Branly em Paris e o debate que o envolveu antes e depois de 2006 (Latour, 2007; L'Estoile, 2007; Price, 2007). Completados mais de dez anos, as iniciativas que o motivaram e os resultados de suas inovações repercutem no campo de estudos sobre museus, e influenciam decisões sobre as visões adotadas, como ocorreu em Barcelona. O modo de exibir posto em discussão no decorrer dos trabalhos para sua criação mantém o debate ativo ainda hoje, motivando novas instituições e respaldando argumentos contra e a favor das escolhas empregadas. Trata-se de desdobramentos contemporâneos de questões mais antigas que acompanham a museologia ao menos desde o século XIX.

A cautela quanto às classificações "artísticas" quando atribuídas aos objetos "antropológicos" foi apontada por Nélia Dias (1991) em sua pesquisa sobre o Musée du Trocadéro no início do século XX em Paris, ressaltando naquela época a distinção entre "arte" como aplicada às produções ocidentais, e um certo "instinct artistique" (Dias, 1991, p. 100), atribuído aos "selvagens". Alice Conklin (2013) também atravessa o tema das reclassificações dos objetos nas trajetórias do Musée du Trocadéro e do Musée de l'Homme nessas primeiras décadas. Para além da 
influência de Georges Henri Rivière e sua biografia mesclada ao mundo da arte francesa, o trabalho junto a Paul Rivet de repensar o primeiro museu, criar o segundo e também o Musée National des Arts et Traditions Populaires, trouxeram questões sobre com quem os museus se propunham a dialogar. Sob influência da crescente popularidade das instituições norte-americanas, a modernização do modo de exibir coleções "exóticas" naquele período esteve impregnada do intuito de abertura dos museus a um público amplo, em detrimento da exclusividade do interesse dos "especialistas do passado" (Conklin, 2013).

As opções entre direcionar as exposições ao público especializado ou ao público leigo, privilegiar a abordagem "estética" ou "científica", estiveram em questão nesse contexto assim como outras escolhas tomadas por antropólogos e museólogos dentro e fora da Europa. De acordo com Stocking Jr. (1985) é difícil identificar um momento da história entre antropologia e museus em que a relação não fosse problemática em algum sentido. Saindo do contexto francês, da mesma forma os debates entre Franz Boas e o General Pitt-Rivers sobre os métodos de exibição dos objetos revelam as peculiaridades das interpretações produzidas pelos museus etnográficos desde a virada do século XIX. Stocking Jr. trata do método aplicado em Oxford a partir da linearidade da exibição dos objetos, numa perspectiva de gradação de escalas de evolução, de modo a enfatizar a forma e a função das peças. Enquanto nos EUA, Boas e sua proposta de contextualização buscavam preservar as múltiplas funções e significados do objeto, numa perspectiva relativista (Stocking Jr., 1985). O curioso, ainda de acordo com o autor, seria verificar a frustração de ambas as propostas, considerando que o museu é mais que um depositário de teorias aplicadas aos objetos. Possui dinâmica própria de interação com coleções e públicos.

As referências a tempos e lugares variados são boas na medida em que auxiliam a compreender debates há muito presentes no mundo da antropologia. No entanto, não são aqui tomados exemplarmente ou categoricamente simétricos, pois o ambiente de Paris dos anos 1930, ou ainda os dos Estados Unidos e Inglaterra na virada do século, não são comparáveis às reivindicações que o campo dos museus vem recebendo especialmente após os anos 1980. A atualização do debate nos dias de hoje parece subverter os posicionamentos, exigindo dos museus produções inovadoras para dar sentido às coleções e museus com passados coloniais. Uma das propostas correntes, e que seria adotada em Barcelona, integra a dinâmica da oposição entre os campos da arte e da 
antropologia. Estes assumem posição entre a defesa da produção artística não ocidental, requerendo lugar às tradições a ela vinculadas e a contestação do uso da estética como conceito universal (Campbell, 2010; Ingold, 1996; Weiner, 1994). Sem mencionar que a defesa da existência de uma "arte não ocidental" produz embates sobre a revisão da prerrogativa da tradição artística ocidental nos debates do campo artístico. Isso significa que também historiadores da arte posicionaram-se de forma heterogênea sobre o tema.

Além do Musée du quai Branly, outros tantos museus europeus têm enfrentado críticas, recebido solicitações de devolução de patrimônios às suas regiões de origem e fechado as portas para repensar a trajetória de exibição de representações do "outro" desde o período colonial. À força das pressões sofridas, mesmo as formas de narrar o "nós" têm sido postas à prova, exigindo dos museus o trabalho de reconstituir interpretações e muitas vezes reposicionar coleções inteiras. Interpretar "esteticamente" os objetos tem sido uma das soluções adotadas como atualização necessária aos museus antropológicos, embora não seja a única e sequer a mais empregada.

\section{A coleção e os museus}

A Coleção Folch é conhecida no campo museológico na Catalunha como um conjunto de objetos "extraeuropeus" reunidos entre 1952 e 1976 por Albert Folch, empresário e membro de uma tradicional família catalã. Segundo alguns comentadores, ${ }^{4}$ durante o serviço militar na então África colonial espanhola nos anos 1940, Folch teria iniciado sua coleção de "objetos exóticos". Stella Folch, sua filha herdeira, detém a conhecida Coleção Folch de objetos etnográficos da África, Ásia, América, Oceania e Espanha.

A história da formação dessa coleção está fortemente atrelada a outros dois importantes personagens: August Panyella, fundador do Museo Etnológico de Barcelona (MEB) em 1949, e Eduald Serra, escultor e colaborador do MEB. Os três realizaram expedições por todos os continentes em conjunto e separadamente, tendo Folch patrocinado algumas delas, articulado compra de objetos a partir

4 Ver Roma e Valls (1998). 
de outros colecionadores fora da Europa para o museu e para sua própria coleção, apoiado e influenciado escolhas de seus colegas na composição das coleções. A origem simultânea de duas coleções, uma privada e outra pública, constituídas pelos mesmos personagens aparece como narrativa entre os profissionais dos museus estudados. Comenta-se que a parceria entre Folch e Serra rendeu a constituição de um grande acervo para o qual buscavam objetos semelhantes durante as viagens, embora o colecionista tivesse interesse prioritariamente "artístico", enquanto seu colega coletava objetos de cunho mais "antropológico".

Tomo "artístico" e "antropológico" como categorias empregadas por meus interlocutores, personagens centrais na concepção do Museo de Culturas del Mundo (MCM) e na reabertura do MEB em 2015, compreendendo tratarem-se de classificações que adquirem funções simbólicas que por sua vez estruturam seu emprego mais pragmático e cotidiano (Gonçalves, 2007). Os objetos em questão sofrem permanentemente processos de transformação social que, como analisa Gonçalves (2007), demarcam identidades e não só separam categorias como as organizam polarizadas, o que nos dá pistas para compreender as ambiguidades das interpretações que acumulam.

Empregadas de forma a classificar lados opostos da divergência que envolveu ambas as instituições, são categorias que definem posicionamento conceitual e ideológico na medida em que agrupam profissionais de um ou outro lado da disputa. Antropólogos, museólogos, historiadores da arte, conservadores e demais profissionais do mundo dos museus são imbuídos de características advindas das classificações que recebem a partir do seu posicionamento na controvérsia. Assim, ainda que determinados pontos de vista sejam exclusivos de antropólogos ou historiadores da arte envolvidos na disputa da Coleção Folch, são muitas vezes tomados pelos envolvidos como intrínsecos à profissão. Isso significa que, de certo modo, no decorrer das acusações, todo um campo do conhecimento passou a ser visto como defensor de conceitos e ideologias de forma homogênea. Algo como se "antropólogos" interpretassem o mundo sempre da mesma forma como os antropólogos envolvidos na controvérsia interpretaram. Embora os campos do conhecimento citados neste trabalho claramente ultrapassem os posicionamentos assumidos por um ou outro personagem.

Assim são também classificados os dois museus: o primeiro deles como "mais artístico" (MCM) e o segundo, "mais antropológico" (MEB), sendo que critérios como visibilidade pública e interesse por parte do governo local parecem 
determinar certa hierarquia entre as definições. No cenário do conflito, "artístico" tem status mais elevado que "antropológico" em alguns momentos, especialmente quando se trata do volume de investimentos financeiros atribuídos a iniciativas classificadas dessa forma; enquanto o contrário ocorre no que se refere a um suposto maior comprometimento intelectual e social do "antropológico" sobre o "artístico". Por hora, é importante acentuar que parte do argumento da criação de um museu acusado de "estético" a partir de uma coleção etnográfica se legitima pelo interesse "artístico" de seu colecionador no momento da aquisição dos objetos. Algo como se o fato de Albert Folch ter sido um colecionador de "arte" corroborasse a decisão de exibir seus objetos a partir dessa chave interpretativa (apesar de que ninguém defende que o MEB retome a interpretação que oferecia nos anos 1950, quando seu nome era Museo Etnológico y Colonial).
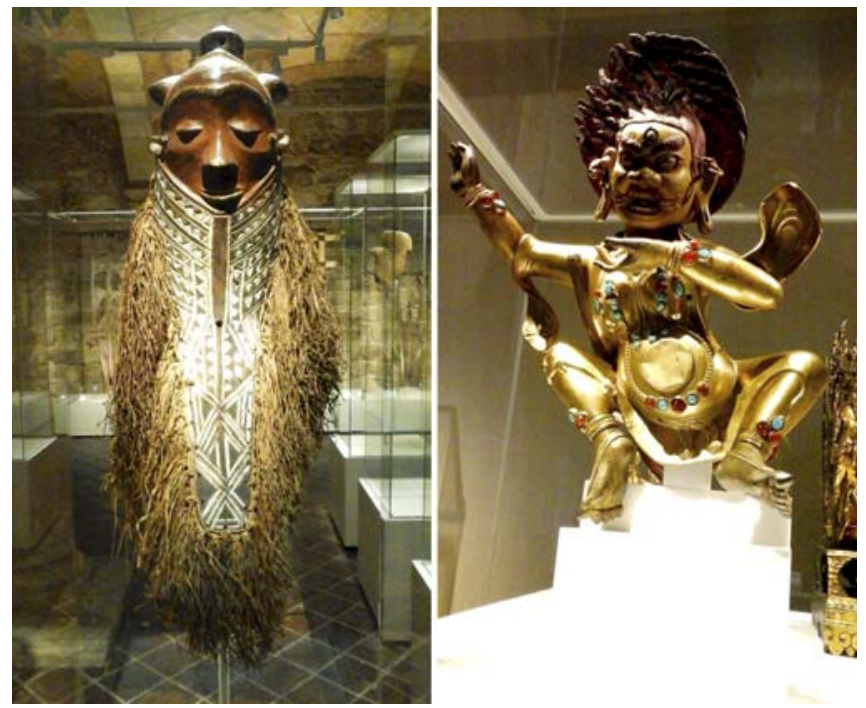

Figura 3. Objetos da Coleção Folch na Sala de África ${ }^{5}$ S Sala de Asia ${ }^{6}$ - MCM (foto: acervo pessoal da autora, 2015).

5 Máscara kiwoyo ou giwoyo, coleção da África, ausência de determinação geográfica, primeiro quarto do século XX, número de inventário MEB CF 290.

6 Palden Llhamo com a Magzor Gyalmo, coleção da Ásia, Tibete, século XIX, número de inventário MEB CF 5833. 
O colecionamento de objetos por dois entusiastas do conhecimento das culturas não europeias contribuiu, cada um a seu modo, para a seleção de patrimônios que formariam a coleção privada da família Folch e o museu público (MEB). A distância que hoje inscreve Folch e Serra em campos conceituais estritos e, consequentemente, o acervo que constituíram, parecia mais tênue na ocasião das colaborações:

A partir del vínculo con el Museo Etnológico, y con un interés especial por el arte y las culturas antiguas, Folch ya no solo viajaba por su cuenta [...], sino que también trabajó de manera altruista en el proceso de adquisiciones para el Museo, hasta el punto de ser un expedicionario habitual más, de hacer donaciones importantísimas y de sufragar parte de los gastos de las expediciones. De hecho, el nivel de colaboración entre Folch y el Museo Etnológico en muchos de los viajes que organizaron juntos fue tal que a veces la línea que separaba dónde empezaban y dónde terminaban las aportaciones de unos y otros era difusa. (Pascual i Miró; Gabriel y Tomàs; Soriano y Marin, 2015, p. 113).

Para a gestão de seu acervo, Albert Folch constituiu uma fundação privada em 1975 que pudesse dar conta da organização dos objetos, pela qual Stella Folch tornou-se responsável após sua morte em 1988. Ali receberam classificações variadas, identificados como "muito bons" e outros não tão antigos ou considerados pelos especialistas em arte como de segunda categoria. No entanto para a Sra. Folch, que aprendeu a amar cada um dos objetos com seu pai, todos seriam iguais em termos sentimentais, muito embora os sentimentos também ordenem e classifiquem as coisas sobre as quais dedicam atenção. Essa foi uma consideração repetida inúmeras vezes durante sua palestra no $\mathrm{MCM}^{7}$ onde hoje a Coleção Folch está exposta. Destacou sua decisão de manter reunidas as peças "sem valor artístico" ou que não entrariam num "museu de primeira linha" porque cada conjunto rememorava a trajetória de seu pai e os lugares por onde passou.

Stella Folch fala a partir de um ponto de vista determinado, como colecionadora ou como guardiã da coleção do pai. Esse lugar permite que ela

$7 \quad$ Em setembro de 2015. 
abstenha-se de opinar sobre a decisão tomada pela gestão municipal entre os anos de 2011 e 2012 sobre o local exato onde seus objetos seriam exibidos após o convênio firmado, tendo em vista que o plano inicial seria expô-los no MEB, e não no recém-criado MCM. Meus interlocutores do Museo Etnológico comentaram sobre sua notável satisfação com a recepção das peças pelo museu, após a assinatura do acordo com a prefeitura, como numa volta para casa, uma vez que a conexão entre os Folch e o MEB articula a origem de ambas as coleções. Interessante observar que a "casa" para a qual os objetos retornavam era um museu europeu, quando outras leituras poderiam interpretar que o local de origem na África ou na Ásia seriam "casa” legítima dessas relíquias.

Ao mesmo tempo, em sua palestra, demonstrou-se orgulhosa e igualmente satisfeita com a exposição no MCM da forma como é hoje apresentada ao público. A colecionadora comentou que no tempo de seu pai foram feitas compras também em condições muitas vezes adversas, ocasiões em que Albert Folch adquiria todo um conjunto "não tão bom". É interessante observar a ordem de critérios da classificação dos objetos: apesar de reconhecer, do ponto de vista da história da arte, que algumas peças seriam "de qualidade inferior", defende a coleção com argumentos sensíveis. De certa forma, a herdeira é a personagem mediadora das esferas em disputa nos dois museus através de sua coleção, e talvez justo por reconhecer-se como tal, sua fala siga direção oposta à controvérsia, optando pela dimensão emocional do usufruto da coleção.

A intenção de manter as peças "vivas", segundo Stella Folch, estaria sendo cumprida na medida em que a coleção passa a interagir e dialogar com seu entorno. Ponto esse em que considera o MCM perfeitamente adequado, estando numa rua de intenso trânsito de público e em frente do Museo Picasso, onde num futuro próximo prevê a esperada parceria que recomponha o ambiente de inspiração das vanguardas artísticas do início do século XX através da "arte tribal".

A relação da cidade com o artista Pablo Picasso enaltece as ocorrências que a ele se relacionam: ruas onde instalou seus estúdios, o café Quatre Gats para o qual pintou o cardápio em 1899, a Carrer Avinyó e as mulheres, os amigos artistas e intelectuais que o cercavam. Localizar-se em frente de seu museu confere prestígio à Coleção Folch, tanto do ponto de vista da valorização de um possível vínculo conceitual, que articula a obra Les demoiselles d’Avignon (1907) à Barcelona e à Sala de África do MCM, como o dar-se a conhecer aos inúmeros visitantes do Museo Picasso. 
Na trajetória dos campos da arte e da antropologia, a ligação entre Picasso e as coleções "exóticas" do Musée du Trocadéro por volta de 1906 em Paris corrobora a coerência da aproximação valorizada em Barcelona. De acordo com James Clifford (2008), no século XX a relação entre surrealismo e etnografia alimentou-se da ruptura com os conceitos predominantes até então de "arte" com A maiúsculo, e "alta" e "baixa" culturas, dissolvendo hierarquias que formulariam as concepções que se seguiram em ambos os campos do conhecimento. A "descoberta" de outros modos de pensar a representação, a estética e a expressão revelavam diferentes sistemas simbólicos alheios à tradição europeia (Rojo de Castro, 2012).

A Coleção Folch chega ao grande público catalão através de uma cessão por 20 anos prorrogáveis, assinada por Stella Folch e pela prefeitura de Barcelona de mais de duas mil peças de todas as partes do mundo, celebrada em 2011. O anúncio da parceria informava que o Museo Etnológico iniciaria remodelação para acolher a coleção, enfatizando a oportunidade de reunir num mesmo espaço coleções "etnográficas" e "artísticas" (Institut de Cultura de Barcelona, 2011). Nesse mesmo anúncio a prefeitura divulgou o plano de reforma do edifício, inaugurado em 1973. ${ }^{8}$ Nesse ínterim, a Coleção Folch foi armazenada e iniciaram-se os estudos de avaliação e catalogação do acervo. Assim, uma vez mais, os objetos seriam reclassificados, migrando de um campo conceitual a outro, de acordo com a interpretação dos profissionais envolvidos nesse processo.

De acordo com meus interlocutores do MEB, a proposta inicial havia sido receber no museu antropológico a Coleção Folch e adotar a perspectiva "etnográfica" dos objetos, relacionando-os à vida social catalã. Com isso, pensavam transmitir o pressuposto comparativo da antropologia, atualizado aos dias de hoje. Para além, notam-se alguns pontos importantes da proposta que desenvolveram nos anos anteriores, desde a entrada de Josep Fornés como diretor do museu em 2008: expor objetos que demonstrem e incentivem o diálogo da Catalunha com as culturas com as quais a região relacionou-se no passado e mantém relações no presente. Quando questionado sobre como então o MEB se preparava para receber e exibir a Coleção Folch, Enric Miró, braço direito do

8 O Museo Etnológico de Barcelona foi inaugurado em 1949 e sempre ocupou o mesmo terreno, embora o edifício tenha sido reconstruído nos anos 1970. 
diretor, explicou em entrevista ${ }^{9}$ que a renovação passaria por esse trabalho já em andamento, e o plano seria classificar os objetos através dos cinco continentes, considerando a Catalunha e sua relação com os países e grupos representados.

Portanto, a expectativa do campo museológico de Barcelona a partir do anúncio desse documento à imprensa seria conhecer a coleção através da exposição de longa permanência a ser montada no Museo Etnológico. De acordo com ex-funcionários, em sua história recente o MEB sofreu com a falta de prestígio junto aos administradores públicos que passaram pela prefeitura de Barcelona. Todos afirmaram que o investimento na reforma do edifício não se realizaria se não fosse a ocasião da recepção desses objetos. O museu então se preparava para redesenhar a mostra e promover alterações no prédio quando uma mudança de planos redefiniu os rumos da instituição.

\section{Da antropologia à arte}

Após a assinatura do convênio para receber a Coleção Folch, o Institut de Cultura de Barcelona (ICUB) ${ }^{10}$ contratou alguns profissionais especialistas para avaliarem os objetos e produzirem um primeiro documento informativo. Essa análise não se restringiu à Coleção Folch, embora o objetivo fosse compreender a dimensão da coleção e considerar suas oportunidades de exibição. Os especialistas envolveram-se também no estudo sobre as coleções públicas do MEB, sendo acompanhados por conservadores e funcionários do próprio museu nesse trabalho.

Tive a oportunidade de entrevistar dois desses especialistas: Elena Martínez, que num primeiro momento esteve dedicada às coleções de objetos da África e Oceania (esta última posteriormente passaria aos cuidados da Cambridge University através de seu Anthropology and Archaeology Museum); e Ricard Bru, especialista em arte japonesa que acompanharia a análise e catalogação dos objetos da coleção da Ásia, junto com o idealizador do futuro Museo de Culturas del Mundo, Josep Lluís Alay. Ambos relataram o extenso trabalho de classificação dos objetos, tanto da Coleção Folch quanto do MEB, muitos deles

9 Em 23 de fevereiro de 2016.

10 Órgão de cultura da prefeitura. 
sem dados e informações suficientes, sendo necessária a consulta a especialistas estrangeiros que colaboraram nessa fase. Nesse trabalho encontraram objetos que nunca haviam sido exibidos, alguns por eles considerados de grande "qualidade". Em entrevista, ${ }_{11}^{11}$ Ricard Bru analisou que a criação do novo museu (MCM) permitiu que Barcelona tivesse acesso a patrimônios públicos nunca antes expostos e que, em sua perspectiva, permaneceriam ocultados não fosse o esforço de sua concepção.

É fundamental destacar que os profissionais convidados eram, em sua maioria, historiadores da arte, o que permite entender que desde esse início já havia a intenção de interpretar os objetos atrelados a esse campo de estudos, ainda que talvez não exclusivamente. Nas entrevistas, os especialistas referiam-se aos objetos utilizando categorias classificatórias como "bons", "de qualidade", "especiais", "de bom nível" e também consideraram critérios como seu valor de mercado, sua antiguidade, autenticidade, unicidade e raridade. Sua avaliação, portanto, partiu de uma análise que tomava a coleção como objetos de "arte extraeuropeus", ainda que os depoimentos dos funcionários do Museo Etnológico demonstrassem que não coincidiam plenamente com essa classificação.

O resultado da análise apontou para a "qualidade artística" do acervo e a possibilidade de construir um projeto de grande visibilidade para a cidade. Nesse momento, o Museu Etnológico tornou-se opção secundária, abrindo espaço para a constituição de um museu de "arte extraeuropeia". A Coleção Folch é então requalificada: antes adequada a ser exibida em um museu tradicionalmente dedicado à disciplina antropológica, ganha novo status, alçando maior prestígio quando considerada capaz de suster a criação de um "museu de arte".

Interessa ressaltar que as decisões sobre o modo de classificar e expor os objetos no então futuro MCM passaram por vários profissionais, inclusive um coletivo formado também por antropólogos, que aos poucos foram retirando-se do grupo ao notarem a tendência do museu de exibir os objetos como arte. Aparentemente, a antropologia e seus porta-vozes perderam espaço para uma interpretação mais estética e dedicada às massas de visitantes não especializados que frequentam os museus de Barcelona. A resposta foi uma onda de acusações sofridas pelo novo museu, rotulado de raso e descontextualizado.

$11 \quad$ Em 30 de novembro de 2015. 


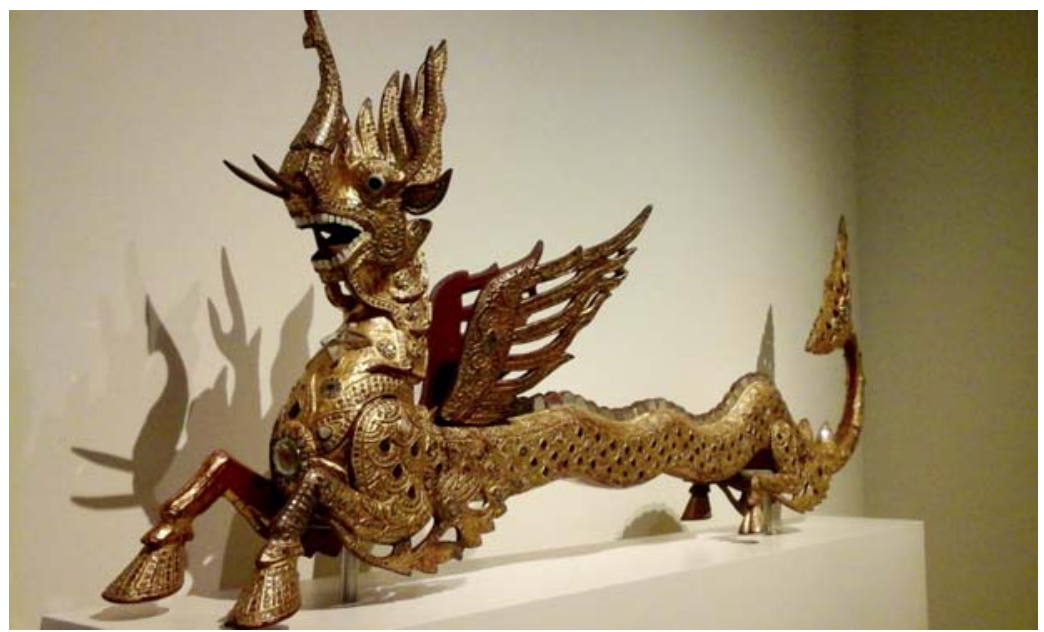

Figura 4. Objeto da Coleção Folch, ${ }^{12}$ Sala de Asia - MCM (foto: acervo pessoal da autora, 2015).

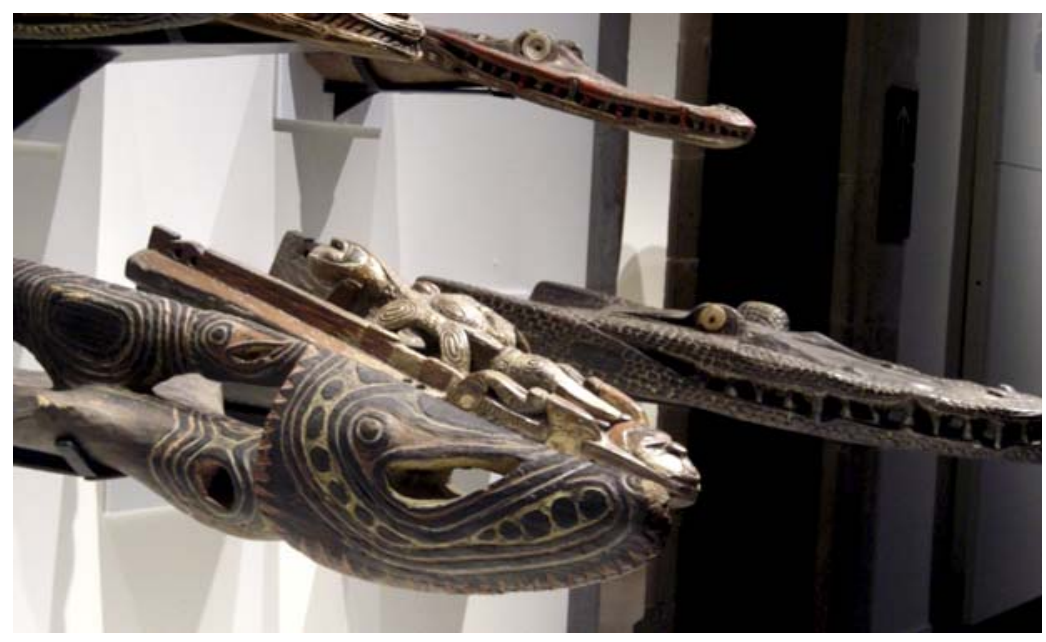

Figura 5. Objetos da Coleção Folch, ${ }^{13}$ Sala de Oceanía - MCM (foto: acervo pessoal da autora, 2015).

12 Suporte de gongo, coleção da Ásia, Birmânia (Myanmar), século XIX, número de inventário MEB CF 5835 .

13 Proas de canoa, dentre elas algumas das culturas Sepik e Iatmul, Indonésia, século XX, coleção da Oceania. 
O período em que ocorre a recepção da coleção pelo Museo Etnológico e a posterior avaliação e classificação dos objetos coincide com a confirmação do esvaziamento de duas casas góticas localizadas lado a lado na Carrer Montcada, rua central do turístico bairro do Born. $O$ anúncio da saída de dois museus ${ }^{14}$ que ocupavam esses espaços encaixou perfeitamente à demanda de um local mais adequado para a construção do novo museu de "arte primitiva", e localizá-lo em frente ao Museo Picasso parecia a oportunidade de criar um importante espaço de arte na cidade.

Em 26 de outubro de 2012, cerca de um ano e meio depois de assinado o comodato entre os Folch e o MEB, a prefeitura anunciou à imprensa a criação do Museo de Culturas del Mundo nas duas citadas casas, já com detalhes bastante precisos sobre seu plano de montagem. $\mathrm{O}$ documento informa sobre o objetivo de situar Barcelona entre as "grandes cidades europeias", reafirmando seu caráter de "capital cultural" através da apresentação e difusão das coleções da Ásia, África, América e Oceania:

El patrimoni artístic i cultural dels pobles no occidentals és avui un element fondamental per a desxifrar les claus de la modernitat i del món del segle XXI. L'evolució de l'etnografia al llarg del S.XX ha transformat el sentit d'aquest tipus de museus, i els ha convertit en una valuosa contribució a la creativitat i a l'excel. lència artística de les grans ciutats europees i nord-americanes. Es precisament la trajectòria d’institucions similars al Museu de Cultures del Món que Barcelona construeix avui la seva pròpia proposta. Es tracta d'una nova iniciativa cultural que posa Barcelona i Catalunya en relació amb el món i, per tant, eixampla la dimensió internacional de la capital del país, Barcelona. (Ayuntament de Barcelona, 2012, p. 2). ${ }^{15}$

14 Museo Barbier-Mueller e o Museo Textil y de la Indumentaria.

15 “O patrimônio artístico e cultural dos povos não ocidentais é hoje elemento fundamental para decifrar as chaves da modernidade e do mundo do século XXI. A evolução da etnografia ao largo do século XX transformou o sentido desse tipo de museu, convertendo-o em uma valiosa contribuição à criatividade e à excelência artística das grandes cidades europeias e norte-americanas. É precisamente a partir da trajetória de instituições similares ao Museu de Culturas do Mundo que Barcelona constrói hoje a própria proposta. Trata-se de uma nova iniciativa cultural que põe Barcelona e Catalunha em relação com o mundo e, portanto, amplia a dimensão internacional da capital do país, Barcelona" (tradução minha). 
As críticas que seriam expostas a partir de então, com a decisão de criar o Museo de Culturas del Mundo para abrigar a Coleção Foch, deixando de lado o plano inicial de exibi-la no Museo Etnológico, foram em sua maioria originadas nos antropólogos das universidades da cidade.

O documento acima citado elenca uma série de museus que serviram de inspiração ao MCM, reiterados pelos meus entrevistados, como Musée du quai Branly, Musée Guimet, British Museum e Metropolitan Museum of Art. Entende-se que a desistência de exibir a Coleção Folch no MEB e criar o MCM tenha contado com um forte componente de visibilidade internacional que se pretendia galgar, daí os demais fatores como localização privilegiada e "interpretação estética" dos objetos favorecerem essa escolha.

Dentre os objetivos divulgados estava o reconhecimento de personalidades que trabalharam pela preservação e manutenção das obras, como Albert Folch, Eduald Serra e August Panyella, os já citados colecionadores e colaboradores do MEB. Destacam-se também os objetivos de apresentar as diferentes culturas do mundo através de seu legado artístico e material; a proposta de discurso multidisciplinar que envolvesse arte, antropologia, história, filologia, religiões, linguística, geografia e filosofia; e o intuito de potencializar o desenvolvimento socioeconômico da cidade através da oferta turística e cultural (Ayuntament de Barcelona, 2012).

Apesar de citar o Museo Etnológico como instituição que contribuiria com sua coleção para a montagem da exposição de longa duração do MCM, os planos para esse museu não constam do documento. Também não trata da decisão de deslocar de um museu a outro a Coleção Folch, nem explica se outra parte dela seria exibida no MEB, como inicialmente previsto. Apesar das declarações oficiais e extraoficiais sobre o intuito de diálogo multidisciplinar do ICUB em relação ao novo museu, o ocultamento das decisões sobre o futuro do MEB e as orientações a ele oferecidas ao longo dessa gestão municipal apontam os primeiros indícios do que se configuraria como um conflito nos meses seguintes.

\section{O ponto de vista dos antropólogos}

Apesar da relatada discordância da direção do MEB em relação às escolhas de seus superiores quanto ao destino da Coleção Folch, ao que tudo indica, 
a controvérsia se instaurou no momento em que a imprensa local difundiu o rumor de que haveria alguns problemas em relação à decisão tomada. Os jornais catalães noticiaram a publicação de um manifesto assinado por 80 professores e pesquisadores da Universitat de Barcelona, denunciando o desmantelamento do que havia de mais "valioso" no acervo do MEB para composição do MCM, e sua redução ao "folclorismo" de um museu sobre tradições, festas e costumes catalães, além de acusações de "fundo ideológico" (Savall, 2014), numa referência ao nacionalismo catalão vigente.

O manifesto foi publicado pelo Grup de Recerca sobre Exclusió i Control Socials (GRECS) da Universitat de Barcelona em dezembro de 2014, grupo composto em sua maioria por antropólogos e sociólogos, alguns deles ex-colaboradores do Museo Etnológico. O texto aborda questões centrais do debate internacional sobre a revisão histórica dos museus de antropologia europeus a partir da descolonização da África e Ásia na segunda metade do século XX. Comenta a origem desses museus criados como instrumento da propaganda e exaltação à empresa colonial, e o que considera duas linhas atuais de debates a respeito: a primeira, uma autorreflexão e até autoincriminação por parte dos museus sobre sua criação e consolidação; e a segunda, a indecisão de responsáveis políticos e técnicos sobre o tema, que leva as instituições à paralisia.

Quanto ao MEB, as acusações foram dirigidas à prefeitura de Barcelona, através do ICUB, de que estaria produzindo a "coisificació de la cultura i identitat catalanes"16 no novo plano museográfico. Tudo isso à revelia de sua direção e funcionários, espoliando o museu de suas coleções "exóticas", a maior parte proveniente de países que integraram o império colonial espanhol, como México, Peru, Marrocos e Guiné Equatorial. Concluem que, portanto, restaria ao MEB exibir as coleções do antigo Museu d'Arts, Indústries i Tradicions Populars ${ }^{17}$ como exemplares das culturas catalães, "seja lá o que isso signifique". O manifesto expõe ainda as dificuldades do trabalho cotidiano do Museo Etnológico, como a formação inadequada de seus funcionários, o baixo orçamento, os obstáculos arquitetônicos do edifício hexagonal e urbanísticos da localização do museu na montanha de Montjuïc.

16 "Coisificação da cultura e identidade catalãs" (tradução minha).

17 O atual MEB narra sua origem a partir das coleções do Museu Etnològic i Colonial (1949) e do Museu d'Arts, Industries i Tradicions Populars (1942). 
Há que se destacar que o GRECS é formado por pesquisadores interessados em acompanhar criticamente as transformações urbanas da cidade, que produzem análises de grande circulação no meio intelectual, cultural e jornalístico de Barcelona, especialmente através das assinaturas de Llorenç Prats e Manoel Delgado. Nessa linha, denunciam a recorrente reclamação dos museus de médio e pequeno porte sobre a cobrança de rentabilidade econômica e das estatísticas de visitantes, segundo o documento, fruto do impulso neoliberal dominante na Barcelona pós-olímpica.

Quanto ao Museo de Culturas del Mundo, evidenciam a semelhança ao processo de criação do Musée du quai Branly em Paris frente aos protestos dos departamentos de antropologia franceses e à satisfação dos marchands de arte, criando um museu voltado ao turismo de massa e à dimensão estética dos objetos, como se "o ato de contemplação devesse ser independente de suas condições de produção e apropriação" (tradução minha). Acusa-o de acrítico e de "consagração do exotismo superficial" ao gosto das elites catalãs, que ocultaria a experiência colonial contida nessas coleções. Por fim, classifica a proposta de exibição da cultura material catalã no Museo Etnológico de Barcelona como "de presépio", referindo-se ao uso de uma definição de cultura engessada e "folclórica", sem diálogo, conflito ou negociação.

A partir da publicação do manifesto, a imprensa ampliou a repercussão para além dos círculos acadêmicos, colhendo declarações de antropólogos e museólogos contra e a favor dos referidos projetos de museus. Nesse ambiente o MCM preparava sua inauguração para o dia 7 de fevereiro de 2015.

Josep Fornés, diretor do Museo Etnológico, reafirmou a expectativa sobre seu posicionamento crítico quanto ao MCM em entrevista. ${ }^{18}$ De fato, considera que "perdemos o museu de culturas, mas conseguimos salvar o etnológico", referindo-se especificamente às questões metodológicas e conceituais da concepção de ambos os museus. O direcionamento do trabalho conduzido por Fornés demonstra que no MEB os objetos são interpretados a partir de outros critérios: mais "antropológico" seria a definição corrente entre os entrevistados, embora na universidade também encontremos críticas a suas iniciativas.

18 Em 10 de fevereiro de 2016. 
Fornés explicou seu modo de trabalho no museu. Chama de "antropologia aplicada" o esforço de responder através dos objetos aos problemas que considera centrais para o debate sobre a Catalunha contemporânea, o que entende ser sua relação com passado e presente, passando por temas "incômodos", como o próprio define:

Un museo de antropología que de verdad actúe como un museo de antropología suele ser incómodo. Aquí, en Japón, en Alemana, en México, en Estados Unidos. Si un museo de antropología habla de arqueología no hay problema, si habla de historia no hay problema, si un museo de antropología habla de estética, de arte, no hay problema. Cuando un museo quiere tener como objeto de estudio la realidad social dinámica y cambiante, conflictiva y problemática, con todos los aspectos de los márgenes sociales y culturales, aquí viene el problema. Este museo ha tenido muchos problemas porque ha ejercido de museo de antropología.

Sua percepção do que deve ser um museu que detém coleções etnográficas é bastante estrita. Considera um insulto a apropriação de objetos extraeuropeus produzidos em contextos específicos e exibidos em museus ocidentais com forte tradição colonial, interpretados como arte à moda europeia. Josep Fornés não está sozinho em seu posicionamento em relação às formas de interpretação de objetos coletados em tempos coloniais. Grandes museus dentro e fora da Europa veem-se atualmente cercados de acusações, solicitações de repatriamento de patrimônios e questionamentos sobre a legitimidade de deter e expor coleções (Ames, 1992; Karp; Lavine, 1991; Sleeper-Smith, 2009).

James Clifford nos anos 1980 já apontava para a perspectiva de diálogo com as populações originárias na recomposição de museus antropológicos, como as experiências que observou no Canadá (Clifford, 1991). Reclassificados como "zonas de contato" no sentido de conformarem-se como tempo e espaço de junção de sujeitos separados geográfica e historicamente (Clifford, 1991), os museus viram-se tensionados a organizarem-se para redefinir seus rumos a partir das críticas decorrentes da descolonização. Redes como o International Committee for Museums and Collections of Ethnography (ICME) do Conselho Internacional de Museus (ICOM), e projetos financiados pela União Europeia como a Red Internacional de Museos de Etnografia (RIME), que se 
desdobrou na rede Sharing a World of Inclusion, Creativity and Heritage (SWICH), reúnem seus profissionais sobre a temática. Buscam repensar o futuro dos museus etnológicos, considerando inclusive se para eles haveria futuro possível (Roigé; Fernández de Paz; Arrieta, 2008), diante da avalanche de reivindicações recebidas e também da variedade de respostas dadas por museus e intelectuais. As iniciativas desenvolvidas pelas instituições constituem por si mesmas um farto campo de pesquisa para antropólogos, museólogos e demais profissionais interessados nas atuais transformações no mundo dos museus.

Por fim, a inauguração do novo MCM teve boa repercussão nos jornais locais e entre o campo dos museólogos e demais interessados na Catalunha, ainda que as primeiras visitas tenham apenas confirmado os principais pontos de críticas por parte dos antropólogos.

Inaugurado o museu em fevereiro, este ofereceu entrada gratuita a todos os visitantes durante cerca de dois meses. Ao final de maio de 2015, as eleições municipais alteraram o cenário político de Barcelona, o que significou a saída dos profissionais responsáveis pela criação do MCM e a ascensão de outros atores políticos. O fim da gestão municipal não resultou, entretanto, na conclusão das obras de reforma do MEB. Ao contrário, as perspectivas de reabertura pareciam pouco promissoras.

Em setembro de 2015, o Museo Etnológico iniciou a comunicação visual pelas ruas da cidade, informando aos moradores sobre sua reinauguração no início de outubro do mesmo ano. Nos cinco meses entre a chegada de um novo partido na prefeitura e reinauguração do museu, houve debates, acordos e novos planos para a conclusão dos últimos detalhes da reforma.

Nos meses seguintes a nova prefeita entregaria nas mãos de Josep Fornés a direção do MEB e do MCM, fundindo ambos os museus em uma só instituição dedicada às culturas de dentro e de fora da Europa, com duas sedes: uma em Montjuïc e outra no Born. A decisão de convidar um dos principais críticos do projeto a dirigir o Museo de Culturas del Mundo soou como o anúncio do seu desmonte por parte dos ex-colaboradores, agravada pelas declarações e demonstrações de que mantinha oposição à visão que o museu projeta.

Assumida a direção de ambos os museus, uma de suas primeiras iniciativas foi suspender a seguinte mostra temporária que inauguraria em 2016 no MCM e replanejá-la. Sua forma de anunciar a chegada de uma outra concepção ao 
novo museu foi contrapor o modelo prioritariamente estético da exposição permanente, de acordo com sua perspectiva, com uma exibição de curta duração que promovesse a interpretação "crítica" daqueles objetos.

Junto a outros profissionais museólogos, conservadores e antropólogos elaborou um projeto para rever as memórias coloniais da Catalunha na então Guinea Española (atual Guiné Equatorial) na primeira metade do século XX. Com essa proposta pretendia enfrentar um discurso corrente na cidade de que os catalães não colonizaram, e que esse fato histórico teria sido obra do império espanhol, mais especificamente de Castilha. Em entrevista, comentou alguns pontos que considera delicados de serem tratados por exposições, como os ganhos econômicos de empresas familiares da Catalunha com a exploração dos recursos naturais da colônia. ${ }^{19}$

A segunda ação da prefeitura no sentido de "solucionar" o problema MCM versus MEB foi reunir um grupo de especialistas e interessados que pudesse debater os pilares de sustentação conceitual de ambos os museus, e propor alguns caminhos para seu futuro. Desse grupo participaram antropólogos, museólogos, historiadores da arte, profissionais que colaboraram anteriormente na criação do MCM e novos convidados. Josep Fornés manteve-se à frente de ambos os museus e consolidou a proposta de transformá-los em um só.

\section{Considerações finais}

A pesquisa de campo realizada em Barcelona adentrou um ambiente de conflito pessoal e institucional entre os museus estudados e seus principais personagens. Ao contrário de trabalhar na comparação de propostas museográficas desenhadas pelos profissionais, este trabalho procura refletir sobre o cenário das transformações dos museus europeus e suas coleções etnográficas. Por sua vez, estas são atualizadas diante das disputas conceituais e ideológicas que atravessam disciplinas acadêmicas e seus conflitos.

A Coleção Folch tornou-se pivô da disputa que envolve mais que profissionais defensores ou acusadores das perspectivas adotadas. Ela mobiliza

19 A exposição Ikunde. Barcelona, Metrópoli Colonial inaugurou em 10 de junho de 2016, no MCM. 
argumentos fazendo ressurgir histórias passadas de colaborações de personalidades catalãs, trajetórias e proposições de políticas culturais ao longo de mais de um século e ativa contrapontos entre "arte" e "antropologia" experimentados por outros museus dentro e fora da Europa. O curioso parece ser justo a capacidade desses objetos de torná-los referência para pontos de vista muito divergentes, seja como um grande museu de arte "não ocidental" que espera valorizar tradições diferentes da europeia, seja como modo de revisar e enfrentar o fantasma do passado colonial.

A partir do trabalho dos profissionais dos museus foi possível conhecer parte dos dilemas que enfrentam para a exibição dos objetos coletados em regiões coloniais ou ex-colônias. E compreender que, qualquer que seja a proposta adotada, encontrarão divergências inerentes às interpretações dos campos do conhecimento. Isso possibilitou ainda refletir sobre o papel desempenhado pelos antropólogos nesse contexto, seja dentro da universidade, do museu ou de instâncias governamentais.

O interesse da pesquisa esteve menos em tomar partido de algum lado da disputa, se é melhor exibir as coleções como "arte" ou "antropologia", e mais em conhecer argumentos, estratégias e opções disponíveis neste árduo trabalho de renovação dos museus e de suas coleções. O modo como cada grupo, a cada momento, define esses objetos interessa na medida em que se tornam fundamentos que legitimam determinadas visões de mundo, e opções conceituais e metodológicas aplicadas aos museus. Ou acusam os mesmos em suas inevitáveis incoerências. E se articulam a um movimento mais amplo em andamento na Europa sobre os debates que visam reconfigurar os museus de antropologia, pós-questionamentos do próprio status da disciplina como campo científico legítimo (Godelier, 2016).

\section{Referências}

AMES, M. M. Cannibal tours and glass boxes: the anthropology of museums. Vancouver: The University of British Columbia Press, 1992.

AYUNTAMENT DE BARCELONA. Creació del nou Museu de Cultures del Món. Mesura de Govern. Consell Plenari Municipal, 26 d'octubre de 2012. 
BARCELONA i els museus com a pessebres. Barcelona, 2014. Disponível em: http:// www.ub.edu/grecs/wp-content/uploads/2014/12/Barcelona-i-els-museus-com-a-pessebres.pdf. Acesso em: 3 jan. 2017.

BENNETT, T. The birth of the museum: history, theory, politics. London: Routledge, 1995.

CAMPBELL, S. A estética dos outros. Tradução de Érica Geisbrecht. Proa: Revista de Antropologia e Arte, v. 1, n. 2, 2010. Disponível em: https://www.ifch.unicamp.br/ojs/ index.php/proa/article/view/2386. Acesso em: 15 jan. 2018.

CLIFFORD, J. Itinerarios transculturales. Barcelona: Gedisa, 1991.

CLIFFORD, J. Colecionando arte e cultura. Revista do Patrimônio Histórico e Artístico Nacional, n. 23, p. 69-89, 1994.

CLIFFORD, J. Sobre a autoridade etnográfica. In: CLIFFORD, J. A experiência etnográfica: antropologia e literatura no século XX. Rio de Janeiro: Editora UFRJ, 2008. p. 132-178.

CONKLIN, A. In the museum of man: race, anthropology and empire in France, 18501950. Ithaca: Cornell University Press, 2013.

DIAS, N. Le Musée d’Ethnographie du Trocadéro (1878-1908): anthropologie et muséologie en France. Paris: Éditions du Centre National de la Recherche Scientifique, 1991.

DUARTE, A. O museu como lugar de representação do outro. Antropológicas, Porto, n. 2, p. 121-140, 1998.

FINDLEN, P. Possessing nature: museums, collecting, and scientific culture in early modern Italy. Berkeley: University of California Press, 1994.

GODELIER, M. En el mundo de hoy, la antropología es más importante que nunca. Revista de Antropología Iberoamericana, v. 11, n. 1, p. 59-77, enero/abr. 2016.

GONÇALVES, J. R. S. O templo e o fórum: reflexões sobre museus, antropologia e cultura. In: CHUVA, M. (org.). A invenção do patrimônio: continuidade e ruptura na constituição de uma política oficial de preservação no Brasil. Rio de Janeiro: Ministério da Cultura/Iphan, 1995. p. 55-66.

GONÇALVES, J. R. S. Teorias antropológicas e objetos materiais. In: GONÇALVES, J. R. S. Antropologia dos objetos: coleções, museus e patrimônios. Brasília: Ministério da Cultura/Iphan, 2007. p. 13-42. (Coleção Museu, Memória e Cidadania).

INGOLD, T. 1993 debate Aesthetics is a cross-cultural category. In: INGOLD, T. (ed.). Key debates in anthropology. London: Routledge, 1996. p. 201-236.

INSTITUT DE CULTURA DE BARCELONA. La Col.lecció Folch formarà part del Museu Etnològic de Barcelona. Barcelona, 2011.

KARP, I.; LAVINE, S. D. Exhibiting culture: the poetics and politics of museum display. Washington: Smithsonian Institution, 1991. 
L'ESTOILE, B. de. Le goût des autres: de l'exposition coloniale aux arts premiers. Paris: Flammarion, 2007.

LATOUR, B. (ed.). Le dialogue des cultures: actes des rencontres inaugurales du Musée du quai Branly, 21 jun. 2006. Paris: Babel: Musée du quai Branly, 2007.

MONTECHIARE, R. Museus em transformação: antropologia e descolonização nos museus de Madrid e Barcelona. 2017. Tese (Doutorado em Antropologia Cultural) Instituto de Filosofia e Ciências Sociais, Universidade Federal do Rio de Janeiro, Rio de Janeiro, 2017.

PASCUAL I MIRÓ, E.; GABRIEL I TOMÀS, A.; SORIANO I MARIN, M. D. Historia de las colecciones. In: MUSEO de Culturas del Mundo: guía de visitas. Barcelona: Ayuntament de Barcelona, 2015. p. 108-123.

PRICE, S. Paris primitive: Jacques Chirac Museum on the Quai Branly. Chicago: University of Chicago Press, 2007.

ROIGÉ, X.; FERNÁNDEZ DE PAZ, E.; ARRIETA, I. El futuro de los museos etnológicos: consideraciones introductorias para un debate. In: CONGRESO DE ANTROPOLOGÍA, 11., Donostia, 2008. Actas [...] Donostia: Ankulegi Antropologia Elkartea, 2008. p. 9-34.

ROJO DE CASTRO, L. Ceci n'est pas une pipe. Cuadernos de Proyectos Arquitectónicos, n. 3, p. 73-85, 2012.

ROMA, J.; VALLS, A. El museu de la Fundación Folch. Revista d'etnologia de Catalunya, n. 13, p. 149-152, 1998.

SAVALL, C. La reducción del Museu Etnològic a lo catalán alarma a los antropólogos. El Periódico, Barcelona. 2 dic. 2014. Disponível em: http://www.elperiodico. com/es/noticias/barcelona/reduccion-museu-etnologic-catalan-alarma-antropologos-3737090. Acesso em: 24 maio 2016.

SLEEPER-SMITH, S. Contesting knowledge: museums and indigenous perspective. Lincon: University Nebraska Press, 2009.

STOCKING JR., G. W. Objects and others: essays on museums and material culture. Madison: The University Wisconsin Press, 1985.

WEINER, J. (ed.). Asthetics is a cross-cultural category. Manchester: Group for Debates in Anthropological Theory, 1994. 